\title{
Factors associated with productivity on automatic milking system dairy farms in the Upper Midwest United States
}

\author{
Justin M. Siewert, ${ }^{*}$ James A. Salfer, $†$ and Marcia I. Endres ${ }^{* 1}$ \\ *Department of Animal Science, University of Minnesota, St. Paul 55108 \\ †University of Minnesota Extension, St. Cloud 56301
}

\begin{abstract}
The objective of this study was to identify housing and management factors associated with productivity on automatic milking system (AMS) dairy farms measured as daily milk yield/AMS and daily milk yield/ cow. Management, housing, and lameness prevalence data were collected from 33 AMS farms in Minnesota and Wisconsin during a farm visit. All farms in the study used free-flow cow traffic. Mixed model analysis of cross-sectional data showed that farms with automatic feed push-up via a robot produced more milk per AMS/day and per cow/day than farms where feed was pushed up manually. New versus retrofitted facility, freestall surface, manure removal system, and the number of AMS units/pen were not associated with daily milk yield per AMS or per cow. Cow comfort index (calculated as number of cows lying down in stalls divided by total number of cows touching a stall) was positively associated with daily milk yield/cow. Prevalence of lameness and severe lameness, number of cows per full-time employee, depth of the area in front of the AMS milking station, and length of the exit lane from the AMS milking station were not associated with daily milk yield per AMS or per cow. Multivariable mixed model analysis of longitudinal AMS software data collected daily over approximately an 18-mo period from 32 of the farms found a positive association between daily milk yield/AMS and average age of the cows, cow milking frequency, cow milking speed, number of cows/ AMS, and daily amount of concentrate feed offered/ cow in the AMS. Factors negatively associated with daily milk yield/AMS were number of failed and refused cow visits to the AMS, treatment time (the time spent preparing the udder before milking and applying a teat disinfectant after milking), and amount of residual concentrate feed/cow. Similar results were also found for daily milk yield on a per cow basis; however, as it
\end{abstract}

Received December 15, 2017.

Accepted April 29, 2018.

${ }^{1}$ Corresponding author: miendres@umn.edu would be expected, average days in milk of the herd were also negatively associated with daily milk yield/ cow. These findings indicate that several management and cow factors must be managed well to optimize AMS productivity.

Key words: automatic milking, robotic milking, milk yield

\section{INTRODUCTION}

Since the first commercial automatic milking system (AMS) installation on a dairy farm in 1992 in the Netherlands, over 25,000 farms worldwide have adopted this technology (Barkema et al., 2015). The adoption and management of AMS most likely varies throughout the world because of national and regional differences in cost and availability of milking labor, current and future projected dairy herd profit margins, environmental regulations, and the social climate allowing farmers to expand. However, across and within regions, management and facility design can also vary considerably. Implementation of AMS on farms in the Upper Midwest United States (upper central region of the country including the states of Iowa, Minnesota, Michigan, and Wisconsin) has grown in recent years. Farms began installing AMS in the Upper Midwest United States around 2009 and industry estimates indicate that over 400 farms in this region now use AMS (personal communications, various AMS dealers). Milk yield/AMS and milk yield/cow are 2 of the factors that can be used to assess productivity in AMS farms. Research on factors affecting productivity of AMS in this region of the United States is limited.

Housing and management strategies vary greatly within the 2-state region of Minnesota and Wisconsin (Salfer et al., 2018). Several farms retrofit AMS into existing facilities, whereas others build new facilities to install AMS. Limited research has been done evaluating aspects of housing design that might influence milk yield/AMS and milk yield/cow. The presence of a large open area in front of the AMS entrance has been suggested to improve cow flow into and around 
the AMS (Rodenburg and House, 2007). A longer exit lane length was indicated by Jacobs et al. (2012) to potentially be associated with improved cow flow when exiting the AMS due to reduced blocking events by other cows in the pen. However, neither of these factors, which can have economic implications for farmers designing facilities with AMS, has been validated in the field. Limited data exist concerning the practice and frequency of feed push-up. Studies conducted in conventional milking systems by DeVries et al. (2003) and Bach et al. (2008) evaluated pushing up feed up to 4 times/d, which is considerably less frequent than what is achieved with automatic feed push-up systems, where feed is generally pushed up every hour or every other hour.

In addition, limited research has been conducted to analyze daily data recorded by the AMS software from a representative number of AMS farms in the same region over an extended period of time to evaluate factors associated with productivity. Tremblay et al. (2016) evaluated weekly data from a large number of farms from across North America; however, regional differences in climate, management practices, and affordable feed resources may lead to differences in management recommendations for different areas. In addition, previous studies have not included factors such as treatment time, average age of the cows, freestall surface, or manure removal system. Therefore, the objective of this study was to investigate the association of daily milk yield per AMS and per cow with housing, lameness prevalence, and management factors on AMS dairy farms in 2 states of the Upper Midwest United States (Minnesota and Wisconsin). It is expected that results of the study will help optimize use of AMS in dairy farms in the United States or help farmers considering AMS.

\section{MATERIALS AND METHODS}

Data on housing, lameness prevalence, and management practices were collected during 1 farm visit from 33 dairy farms in 2 states of the Upper Midwest (Minnesota and Wisconsin) followed by remote collection of data from the AMS software for a period of approximately 18 mo (mid-2013 to the end of 2014). All farms in the current study used free-flow cow traffic (i.e., cows were allowed to move between the resting area, AMS unit, and feeding area freely). These farms were estimated (based on dealer information) to represent the majority $(>85 \%)$ of confinement farms with free-flow traffic AMS in these 2 states at the time of initiation of the current study. Observational data of housing design were collected from each pen where an AMS was used to milk the cows. Twenty-three percent of farms milked recently calved cows (up to a week after calving) in a conventional milking system; those cows and their environment were not included in the current study. Only 1 farm in the current study had Jerseys and all other farms had primarily Holsteins; removing the farm with Jerseys from the data set did not alter any of the analysis results; therefore, the farm was kept in the final data set used for analysis.

Housing design measurements included depth of area in front of the AMS unit (m) and length of the protected lane at the exit of the AMS (m). Other observations included whether the dairy selected to build new facilities or retrofit existing facilities when installing the AMS, number of AMS units installed per pen, what type of freestall surface was used, and what type of manure removal system was used in the AMS pen(s). Freestall surface was categorized as mattresses, deep sand, or waterbeds. Two farms using bedded-pack systems were excluded from the analysis of freestall surface. Manure removal system was categorized as either automatic scraping of alleys, manual scraping, or slatted alley floor with a manure containment pit below the barn. The number of cows/full-time employee (FTE) at the time of visit was also collected. This included employees working with the dairy operation and did not include other areas of the farm such as crop production. All lactating cows in the current study were housed in a barn and did not have access to pasture. Number of AMS units was categorized into either 1 AMS unit/pen or $>1$ AMS unit/pen.

Cow comfort index (CCI) was calculated by dividing the number of cows lying in a stall by the number of cows touching a stall (cows lying in the stall plus cows standing with 2 or 4 feet in the stall). This index could not be calculated on 2 farms because they used a bedded-pack housing system (therefore did not have freestalls) and 3 other farms for which this measurement could not be collected. Espejo and Endres (2007) found CCI to be negatively associated with lameness prevalence in a study with conventional freestall farms in Minnesota. Farms in the current study were not overcrowding stalls (mostly at 100\%); therefore, stall stocking density was not investigated because there was not enough variation among farms.

A minimum of $30 \%$ of cows in all pens as a representative sample of the herd (Endres et al., 2014) were scored for locomotion by a single trained observer using a 5-point scoring method (Flower and Weary, 2006), where $1=$ normal, $2=$ imperfect locomotion, $3=$ lame, and scores of 4 and $5=$ severely lame. Cow identifications were recorded by the observer to avoid scoring the same cow more than once; cows were scored by the observer as they walked in the freestall alleys for a minimum of 6 strides without impediment, and 
approximately every third cow was scored. Locomotion score data were used to calculate prevalence of lameness (percent of cows scoring $\geq 3$ ) and severe lameness (percent of cows scoring $\geq 4$ ) in each pen.

Daily data recorded by the AMS software for a period of approximately 18 mo were used to summarize information on AMS use and productivity of the herd. The variables used in the analysis included daily milk yield (per cow and per AMS; kg), milking visits (number of successful milking visits to the AMS per cow/d), refused visits (number of visits to the AMS per cow/d where no milking attachment was attempted because of milking permission settings), failed visits (number of visits to the AMS per cow/d where the attempted milking was not successful), concentrate feed offered (daily amount of concentrate feed offered in the AMS/ cow; $\mathrm{kg}$ ), residual feed (residual concentrate feed/cow programmed by the feed tables but not offered because the total time in the milking stall was less than the time required to feed this amount at the preset feed delivery rate; $\mathrm{kg}$ ), milking speed (average/cow per visit; $\mathrm{L} / \mathrm{min}$ ), milking time (average time/cow per visit; milking units are attached; s), treatment time (average time required/cow per visit to prepare the udder for milking and then post dip after milking; s), average DIM, average age of the cows in the herd (mo), and number of cows/AMS. One farm was excluded from this analysis due to missing data.

\section{Statistical Analysis}

Descriptive Data. The FREQ procedure in SAS 9.4 (SAS Institute Inc., Cary, NC) was used to calculate the frequency of new versus retrofitted facilities where the AMS was installed, as well as freestall surface, manure removal system, number of AMS units/ pen, and feed bunk management system. Descriptive statistics were computed using the MEANS procedure (SAS 9.4). When the data were normally distributed, mean \pm standard deviation are reported, and when data were nonnormally distributed, median, interquartile range (IQR), and range are reported. Cow comfort index, prevalence of lameness, cows/FTE, average age of the cows in the herd, milking visits, concentrate offered, residual feed, milking time, treatment time, and cows/AMS had normal distribution. Nonnormally distributed factors included severe lameness, depth of the area extending out from the AMS entrance, length of the exit lane from the AMS, average DIM, refused visits, failed visits, and milking speed.

Cross-Sectional Data. Data from categorical variables were used to evaluate their association with average milk yield per AMS/day and per cow/day us- ing univariable analysis (1-way ANOVA). The PROC MIXED in SAS with the LSMEANS statement and PDIFF $=$ ALL option was used to determine differences among categories. Farm was used as the experimental unit $(\mathrm{n}=33)$. Categorical variables included in the univariable analysis were new or retrofitted AMS facility, manure removal system, freestall surface, AMS units/pen, and feed push-up method. Continuous variables of housing and management and their association with milk yield per AMS/day and per cow/day were analyzed using simple linear regression. The model was fit using PROC MIXED (SAS 9.4) for their association with average milk yield/AMS per day and milk yield/ cow per day using univariable analysis. Farm was used as the experimental unit $(\mathrm{n}=33)$. Continuous variables included in the analysis were CCI, lameness prevalence, severe lameness prevalence, cows/FTE, depth of the open area extending out from the AMS entrance, and length of the exit lane from the AMS. Model assumptions were evaluated using residual plots.

Longitudinal Data. Longitudinal data collected daily from the AMS software were used to evaluate the association of those factors with milk yield per AMS/ day and per cow/day. Fixed factors evaluated include average DIM and average age of the cows in the herd; number of milking, failed, and refused visits to the AMS; concentrate feed offered and residual feed; milking speed; milking time, treatment time; and number of cows/AMS. A univariable linear mixed analysis was first conducted with each variable and the 2 outcomes of interest: milk yield/AMS per day and milk yield/cow per day. Factors with a $P<0.3$ were included in the initial multivariable linear mixed model (Proc MIXED, SAS 9.4). Backward elimination was used to remove nonsignificant factors until all remaining factors had a $P<0.05$ in the final model. Farm was included in the models as a random effect. Model assumptions were evaluated using residual plots.

\section{RESULTS AND DISCUSSION}

\section{Descriptive Statistics}

Cross-Sectional Data. Number of cows/FTE was $89.7 \pm 34.0$. Fifty-five percent of the farms built new facilities when installing the AMS and 45\% retrofitted existing facilities to accommodate the new milking system. For the freestall surface, $48 \%$ of the farms had mattresses, $39 \%$ used sand bedding, and $12 \%$ had waterbeds. To remove manure in the alleyways of the pens, $52 \%$ of the farms had automatic scrapers, $33 \%$ scraped the pens manually, and $15 \%$ had slatted floors. Pens were designed with 1 AMS/pen on $58 \%$ of the 
farms and with 2 or more AMS/pen in at least 1 of the pens on $42 \%$ of the farms. Only $3 \%$ of the farms had 3 robots in 1 pen and no farms had $>3$ robots per pen.

A robotic feed pusher was used on $31 \%$ of the farms, manual pushing up of the feed on $50 \%$ of the farms and a fixed bunk to contain the feed ("H" or J" type of bunk) on $19 \%$ of the farms.

The CCI was $75.8 \pm 11.7 \%$ (mean $\pm \mathrm{SD}$ ). Lameness prevalence was $25.6 \pm 10.8 \%$ and median severe lameness prevalence was $4.4 \%$ (IQR 5.6; range 0 to 16.1). Median depth of the area at the entrance to the AMS was $6.1 \mathrm{~m}$ (IQR 1.6; range 3.1 to 11.5). Median length of the exit lane from the AMS was $2.6 \mathrm{~m}$ (IQR 2.7; range 0.3 to 8.5). Average milk yield on a per cow per day basis varied considerably among farms, ranging from about $20.9 \mathrm{~kg} /$ cow per d to almost $40 \mathrm{~kg} /$ cow per d.

Longitudinal Data. Milk yield was $33.2 \pm 5.3 \mathrm{~kg}$ per cow/d and 1,861.1 $\pm 380.4 \mathrm{~kg}$ per AMS/d. Median herd size was 115.1 cows (IQR 94.5; range 55.7 to 472.0) with $55.8 \pm 6.1$ cows/AMS unit. Median DIM was 173 (IQR 14.6; range 142.8 to 241.6). Average age of the cows in the herd was $48.9 \pm 4.8$ mo. Farms averaged $2.80 \pm 0.24$ milking visits/d, had a median of 0.81 refused visits/d (IQR 0.53; range 0.38 to 3.47 ), and a median of 0.076 failed visits/d (IQR 0.033; range 0.026 to 0.36). Amount of concentrate offered in the AMS averaged $5.01 \pm 0.84 \mathrm{~kg} / \mathrm{cow}$ and residual feed averaged $0.27 \pm 0.12 \mathrm{~kg} / \mathrm{cow}$. Median cow milking speed was $2.74 \mathrm{~L} / \mathrm{min}$ (IQR 0.31; range 2.29 to 5.00). Milking time averaged $331.8 \pm 33.1 \mathrm{~s}$ and treatment time averaged $121.8 \pm 22.0 \mathrm{~s}$.

\section{Cross-Sectional Data Analysis}

No association was observed between number of cows/FTE and productivity in the current study. In addition, we did not find a difference in productivity between new and retrofitted facilities (Table 1). This could be because farms in the current study that chose to retrofit had existing facility designs that allowed for proper retrofitting or understood how to best modify retrofitted barns to optimize AMS productivity. Most of the retrofitted facilities in our study had proper stall sizes, good cow comfort, and adequate feed bunk and water space. Whether to build new or retrofit existing facilities when transitioning to an AMS has been suggested to be an important aspect of the decision making process for farmers before making the transition (Rodenburg, 2010). Many farmers wonder if investing in a new barn will result in sufficient increase in productivity and labor efficiency to pay for the additional investment. Tremblay et al. (2016) also reported that building a new facility or retrofitting existing facilities was not associated with milk yield/AMS. The decision to build new or retrofit existing facilities will likely be influenced by other factors on the farm, such as usability of facilities, differences in labor efficiency, and cost of building new versus retrofitting. Rodenburg (2010) recommended that farms weigh the total costs and benefits of retrofitting compared with building new before making a final decision.

Manure removal system and freestall surface were not associated with milk yield per AMS or per cow. Eighty percent of the farms with slatted floor barns used an automatic scraping robot (Lely Discovery, Lely Industries N.V., Maassluis, the Netherlands) to push manure through the slats. Although no association was found between manure removal system and milk yield in the current study, Rodenburg (2004) suggested that use of automatic scrapers or slats could be advantageous because entry of machinery into the pen can be disruptive to the cows. In addition, barns with automatic scrapers could potentially be cleaner as there could be more runs through the barns scraping the floor.

The optimal number of AMS units/pen has been a discussion topic in the industry as farms are deciding how to design their barns (Rodenburg, 2010). Many factors play into this decision including herd size, grouping strategies, and ease of fetching cows that do not voluntarily visit the AMS (Rodenburg, 2010). We did not find a difference in milk yield per AMS or per cow between farms with $1 \mathrm{AMS} /$ pen and those with $>1$ AMS/pen; most of the farms in our study $(97 \%$ of the farms) had at the most 2 AMS/pen; only one

Table 1. Least squares means of milk yield per automatic milking system (AMS) unit/day and cow/day for categorical variables on 33 dairy farms in Minnesota and Wisconsin

\begin{tabular}{lcc}
\hline & \multicolumn{2}{c}{ LSM (kg) } \\
\cline { 2 - 3 } Variable & Yield per AMS & Yield per cow \\
\hline New/retrofit facility & $1,834.2$ & 32.7 \\
New & $1,893.5$ & 33.8 \\
Retrofit & $1,810.9$ & 31.9 \\
Freestall surface & $1,950.8$ & 34.9 \\
Mattress & $1,960.5$ & 35.0 \\
Sand & $1,900.3$ & 33.6 \\
Waterbed & $1,799.8$ & 33.3 \\
Manure removal & $1,862.8$ & 33.9 \\
Automatic scraping & & \\
Manual scraping & $1,834.5$ & 32.0 \\
Slatted floor & $1,897.2$ & 34.9 \\
AMS/pen & & \\
1/pen & $2,078.1^{\mathrm{a}}$ & $36.4^{\mathrm{a}}$ \\
>1/pen & $1,726.4^{\mathrm{b}}$ & $31.5^{\mathrm{b}}$ \\
Feed push-up & $1,894.7^{\mathrm{ab}}$ & $33.5^{\mathrm{ab}}$ \\
Mutomatic feed push-up & & \\
Contained bunk ("H" or "J") & & \\
\hline
\end{tabular}

${ }^{\mathrm{a}, \mathrm{b}}$ Means with different superscripts within variables differ $(P<0.05)$. 
farm had 3 AMS/pen and no farms had $>3$ AMS/pen. Our results are in contrast to Heurkens et al. (2016) in the Netherlands and Tremblay et al. (2016) in North America, where farms with 2 or more AMS/pen had higher milk yield per AMS than farms with 1 AMS/ pen. Producers have reported that when an AMS unit is out of use for an extended period of time due to repairs being performed (more than a couple hours), they have experienced less dramatic production losses when there is another AMS unit in the pen that can continue to be accessed for milking (Rodenburg and House, 2007). In addition, cows have more choices and there are fewer opportunities for dominant cows to dominate an AMS milking station on farms with $>1$ AMS/pen.

Feed push-up method was associated with milk yield per AMS and per cow per day in the current study. Farms with automatic feed push-up produced $352 \mathrm{~kg}$ more milk/AMS and $4.9 \mathrm{~kg}$ more milk/cow per day than farms that manually pushed up feed (Table 1). This difference could be equivalent to approximately $\$ 45,000$ more/AMS per yr for farms using automatic feed push-up (assuming a milk price of $\$ 0.35 \mathrm{USD} / \mathrm{kg}$; excluding costs of operating, maintenance, and so on). Milk yield for farms with a bunk where feed push-up was not necessary was intermediate and not different from the farms where feed was either automatically or manually pushed up. Automatic feed push-up allows for this task to be performed on a consistent schedule and multiple times/day. An increased frequency of feed push-up is expected to improve feed access for the cows and help keep feed well mixed at the bunk, potentially reducing the opportunity for sorting. Previous research with conventional systems has not found an association between feed push-up frequency and milk yield (DeVries et al., 2003; Bach et al., 2008); however, these studies only pushed up feed up to 4 times/d, which is similar to the feed push-up schedule performed on many of the farms in the current study that manually pushed up feed. In addition, AMS farmers may not be in the barn as frequently or consistently to push up feed as when milking with a conventional system. This may result in some days where feed push-ups are performed less frequently than what the producer reported, having a negative effect on milk yield. The differences between feed bunk management systems might not be the result of the actual activity of pushing up feed, as DeVries et al. (2003) found pushing up feed in conventional systems to have very limited effect on stimulating cows' visits to the feed bunk, especially in comparison to feeding and milking activities. This could be different in AMS farms and deserves further investigation. Generally, both the automatic push-up and fixed bunk system provide for feed being accessible on a continuous basis. Management factors, such as targeted refusal rates, which were not measured in this study, could help explain why farms using a contained bunk did not produce more than farms using manual feed push-up.

The CCI, a measure of freestall usability and comfort was positively associated with milk yield/cow $(P=$ 0.035 ), indicating this may be a simple, useful tool to be used on farms when evaluating cow comfort. Espejo and Endres (2007) found CCI (referred to in that study as cow comfort quotient) as having a negative association with lameness prevalence in conventional freestall farms. Although CCI was associated with milk yield in the current study, both lameness and severe lameness prevalence were not found to be associated with milk yield/AMS or per cow. This contradicts the findings of Bach et al. (2007) where increased lameness prevalence was associated with decreased milking frequency and milk yield in AMS farms. We suggest that factors such as potentially increased fetching of lame cows on farms in the current study (which we did not measure) or changes in lameness prevalence over the period of time when milk yield data were collected (as lameness prevalence was only assessed at 1 visit), may have affected the association lameness had with milk yield in the current study.

Depth of the area in front of the AMS (median 6.1 $\mathrm{m}$; IQR $1.6 \mathrm{~m}$; range 3.1 to 11.5 ) was not associated with milk yield per AMS or per cow. This variable was included in our analysis because discussions of our team with various consultants suggested that having less open space would increase the likelihood of cows blocking the entrance, therefore causing cows to remain standing idle for longer periods of time waiting to enter the AMS. This could cause a reduction in AMS milking visits, leading to reduced milk yield. Based on field experience, Rodenburg and House (2007) stated that having a larger open area in front of the AMS improved cow flow. It may be that the area in front of the AMS was generally adequate on the farms in the current study and not limiting cow flow.

We found no association between length of the exit lane from the AMS (median $2.6 \mathrm{~m}$; IQR 2.7; range 0.3 to $8.5 \mathrm{~m}$ ) with milk yield per AMS or per cow. It has been suggested that longer exit lanes from the AMS help facilitate improved cow flow through the AMS, and help prevent blocking events where the AMS is unavailable for subsequent milkings due to a cow being unable to exit the AMS unit (Jacobs et al., 2012).

\section{Longitudinal Data Analysis}

All factors from the univariable analyses met the criteria for inclusion in the multivariable regression models $(P$-values $<0.16)$. In the milk yield/cow per day multivariable model (Table 2), no variables were 
Table 2. Multivariate analysis of farm-level factors and their association with milk yield per cow ( $\mathrm{kg} / \mathrm{d})$ on 32 automatic milking system (AMS) dairy farms in Minnesota and Wisconsin

\begin{tabular}{lrrr}
\hline Variable & Estimate & $\mathrm{SE}$ & $P$-value \\
\hline Average DIM & -0.0027 & 0.0005 & $<0.0001$ \\
Average age of cows in the herd (mo) & 0.0888 & 0.0048 & $<0.0001$ \\
Average milking visits & 6.4683 & 0.0634 & $<0.0001$ \\
Average refused visits & -0.4145 & 0.0208 & $<0.0001$ \\
Average failed visits & -0.5476 & 0.1126 & $<0.0001$ \\
Average concentrate feed offered (kg) & 1.2134 & 0.0267 & $<0.0001$ \\
Average residual feed (kg) & -3.2611 & 0.1026 & $<0.0001$ \\
Milking speed (L/min) & 5.3412 & 0.0579 & $<0.0001$ \\
Milking time (s) & 0.0633 & 0.0005 & $<0.0001$ \\
Treatment time (s) & -0.0183 & 0.0009 & $<0.0001$ \\
Cows/AMS & 0.0079 & 0.0021 & 0.0001 \\
\hline
\end{tabular}

removed with backward elimination, as all had an association $(P<0.001)$ with the outcome variable. Average DIM was removed from the milk yield/AMS per day multivariable model $(P=0.072$; Table 3$)$.

Average number of milking visits/d was positively associated $(P<0.0001)$ with milk yield per cow and per AMS. This supports the findings of Løvendahl and Chagunda (2011) in an analysis of individual cow data where they also found a positive effect on milk yield from increased milking visits/day on AMS farms. Wagner-Storch and Palmer (2003) also found increased milk yield in an AMS compared with a conventional milking system and found the greatest contributor to the increased milk yield was an increase in milking frequency.

Average number of refused and failed visits per cow/ day were negatively associated $(P<0.0001)$ with daily milk yield per cow and per AMS. Refused visits are a result of cows visiting the AMS before the minimum time interval in between milkings from permission settings. Failed visits can result from multiple factors caused by either the cow or equipment malfunctions and can also be created by cows not being milked properly. Tremblay et al. (2016) also found a negative association of refused and failed visits to the AMS with milk yield. Bach and Busto (2005) found quarters that experienced milking failure produced a similar amount of milk at the subsequent milking event but had lower milk yield when measured on a per hour basis due to the increased milking interval.

Average concentrate offered/cow per day was positively associated $(P<0.0001)$ with daily milk yield, both per cow and per AMS; with farms offering more concentrate generally obtaining higher milk yield. This could be just the result of 2 variables being related. Normally cows are fed according to a feed table, where they are offered more concentrate the more milk they produce. To take advantage of the benefits of precision feeding and limit the amount of residual feed in the AMS, Bach and Cabrera (2017) recommended limiting concentrate allowance in the AMS to $<4 \mathrm{~kg} / \mathrm{d}$ and 1 to $1.5 \mathrm{~kg} /$ visit. Average residual feed was negatively associated with daily milk yield per cow and per AMS in the current study. This contradicts the findings of Tremblay et al. (2016) where a positive association was found between milk yield and average residual feed.

Milking speed had a positive association $(P<$ 0.0001) with daily milk yield per cow and per AMS, which probably indicates that greater milking speeds are associated with an overall increase in the efficiency of the system. Tremblay et al. (2016) also found that milking speed was positively associated with milk yield.

Table 3. Multivariable analysis of farm-level factors and their association with milk yield $(\mathrm{kg} / \mathrm{d}) /$ automatic milking system (AMS) on 32 AMS dairy farms in Minnesota and Wisconsin

\begin{tabular}{lrrc}
\hline Variable & Estimate & $\mathrm{SE}$ & $P$-value \\
\hline Average age of cows in the herd (mo) & 10.25 & 0.29 & $<0.0001$ \\
Average milking visits & 328.51 & 3.85 & $<0.0001$ \\
Average refused visits & -27.11 & 1.30 & $<0.0001$ \\
Average failed visits & -59.27 & 7.06 & $<0.0001$ \\
Average concentrate feed offered (kg) & 63.28 & 1.67 & $<0.0001$ \\
Average residual feed (kg) & -165.53 & 6.43 & $<0.0001$ \\
Milking speed (L/min) & 295.97 & 3.63 & $<0.0001$ \\
Milking time (s) & 3.53 & 0.03 & $<0.0001$ \\
Treatment time (s) & -0.78 & 0.06 & $<0.0001$ \\
Cows/AMS & 29.70 & 0.13 & $<0.0001$ \\
\hline
\end{tabular}


Hogeveen et al. (2001) found milking speed (described in their study as milk flow rate) to be positively associated with longer milking intervals. However, greater milking speeds have also been associated with elevated SCC (Slettbakk et al., 1990). Therefore, identifying optimal milking speeds may be more desirable than striving for maximum milking speed to achieve increased AMS efficiency and good cow health.

Treatment time was negatively associated $(P<$ 0.0001 ) with both daily milk yield per cow and per AMS. Treatment time averaged $121.8 \pm 22.0 \mathrm{~s} / \mathrm{cow}$ per visit. Longer treatment time represents less time the AMS is available for milking, which may cause a reduction in number of cows that can be successfully milked with an AMS unit or the frequency at which cows can be milked. However, the association between longer treatment time and lower milk yield/cow is not as obvious. We could expect that longer treatment time could result in better milk let down and faster milking, and therefore potentially greater milk yield per cow. However, longer treatment time due to more attachment difficulty with repeated attempts might result in less frequent cow visits or cow discomfort, resulting in lower milk yield. Further research is warranted.

Number of cows/AMS was positively associated $(P<$ $0.0001)$ with daily milk yield/AMS. However, number of cows per AMS was also positively associated with daily milk yield/cow per day $(P=0.0001)$. Tremblay et al. (2016) also reported a positive association between number of cows/AMS and milk yield/cow. Our results might indicate that stocking levels per AMS unit in the current study were generally at or below the capacity of the AMS and not exceeding the number of cows the system could successfully handle. It is possible that milk yield/cow per day could be negatively affected by a higher number of cows/AMS. More research is needed to determine the ideal number of cows/AMS on US farms to optimize the amount of milk produced per cow and per AMS.

\section{CONCLUSIONS}

Various factors were found to influence productivity on AMS dairy farms in the current study and most of these factors can be managed by the farmer. More frequent feed push-up and good stall comfort appeared to be important farm level factors to achieve high milk yield on AMS farms. In addition, the amount of concentrate cows consume in the AMS, the frequency cows are successfully milked per day, how fast they are milked, and how many cows are milked/AMS were all factors associated with greater productivity. Efforts should be taken to minimize failed visits and optimize refused visits to the AMS to improve the efficiency of AMS use and increase cow productivity.

\section{ACKNOWLEDGMENTS}

We thank all the dairy producers who participated in the study. We also thank Luis Espejo (St. Augustine, FL) for help with statistical analysis and Lucas Salfer (Dassel, MN) for collection of on-farm observations, cow locomotion scores, and producer questionnaire responses. In addition, we thank Lely Industries N.V. (Maassluis, the Netherlands) for technical help with software data collection and Kelly Froelich and Michael Schmitt (both University of Minnesota) for help with software data entry. We also thank David W. Kammel (University of Wisconsin, Biological Systems Engineering Department, Madison) for his input on housing data collection and help with enrollment of Wisconsin AMS farms. Justin Siewert was partially supported by a Department of Animal Science Fellowship (University of Minnesota) and the John Brandt Memorial Scholarship (Land O'Lakes Inc., St. Paul, MN). This project was partially supported by Hatch Funds from the USDA National Institute of Food and Agriculture.

\section{REFERENCES}

Bach, A., and I. Busto. 2005. Effects on milk yield of milking interval regularity and teat cup attachment failures with robotic milking systems. J. Dairy Res. 72:101-106. https://doi.org/10.1017/ S0022029904000585.

Bach, A., and V. Cabrera. 2017. Robotic milking: Feeding strategies and economic returns. J. Dairy Sci. 100:7720-7728. https://doi .org/10.3168/jds.2016-11694.

Bach, A., M. Dinarés, M. Devant, and X. Carré. 2007. Associations between lameness and production, feeding and milking attendance of Holstein cows milked with an automatic milking system. J. Dairy Res. 74:40-46. https://doi.org/10.1017/S0022029906002184.

Bach, A., N. Vallis, A. Solans, and T. Torrent. 2008. Associations between nondietary factors and dairy herd performance. J. Dairy Sci. 91:3259-3267. https://doi.org/10.3168/jds.2008-1030.

Barkema, H. W., M. A. G. von Keyserlingk, J. P. Kastelic, T. J. G. M. Lam, C. Luby, J.-P. Roy, S. J. LeBlanc, G. P. Keefe, and D. F. Kelton. 2015. Invited review: Changes in the dairy industry affecting dairy cattle health and welfare. J. Dairy Sci. 98:7426-7445. https://doi.org/10.3168/jds.2015-9377.

DeVries, T. J., M. A. G. von Keyserlingk, and K. A. Beauchemin. 2003. Short communication: Diurnal feeding pattern of lactating dairy cows. J. Dairy Sci. 86:4079-4082. https://doi.org/10.3168/ jds.S0022-0302(03)74020-X.

Endres, M. I., K. M. Lobeck-Luchterhand, L. A. Espejo, and C. B. Tucker. 2014. Evaluation of the sample needed to accurately estimate outcome-based measurements of dairy welfare on farm. J. Dairy Sci. 97:3523-3530. https://doi.org/10.3168/jds.2013-7464.

Espejo, L. A., and M. I. Endres. 2007. Herd-level risk factors for lameness in high-producing Holstein cows housed in freestall barns. J. Dairy Sci. 90:306-314. https://doi.org/10.3168/jds.S0022 $-0302(07) 72631-0$.

Flower, F. C., and D. M. Weary. 2006. Effect of hoof pathologies on subjective assessment of dairy cow gait. J. Dairy Sci. 89:139-146. https://doi.org/10.3168/jds.S0022-0302(06)72077-X. 
Heurkens, D., C. Kamphuis, and A. J. van der Kamp. 2016. Effects of free-stall barn layout on efficiency of Dutch dairy farms with an automatic milking system. Pages 157-162 in Proc. Precision Dairy Farming Conf. 2016. C. Kamphuis, and W. Steeneveld, ed. Wageningen Academic Publishers, Wageningen, the Netherlands, 21-23 June 2016, Leeuwarden, the Netherlands.

Hogeveen, H., W. Ouweltues, C. J. A. M. de Koning, and K. Stelwagen. 2001. Milking interval, milk production and milk flow-rate in an automatic milking system. Livest. Prod. Sci. 72:157-167. https://doi.org/10.1016/S0301-6226(01)00276-7.

Jacobs, J. A.. K. Ananyeva, and J. M. Siegford. 2012. Dairy cow behavior affects the availability of an automatic milking system. J. Dairy Sci. 95:2186-2194. https://doi.org/10.3168/jds.2011-4749.

Løvendahl, P., and M. G. G. Chagunda. 2011. Covariance among milking frequency, milk yield, and milk composition from automatically milked cows. J. Dairy Sci. 94:5381-5392. https://doi.org/10 .3168/jds.2010-3589.

Rodenburg, J. 2004. Housing considerations for robotic milking. ASAE Paper No. 044189, 2004 ASAE Annual Meeting, American Society of Agricultural and Biological Engineers, St. Joseph, MI. https:// doi.org/10.13031/2013.16897

Rodenburg, J. 2010. Robotic barn design. WCDS Adv. Dairy Technol. 22:277-292. https://wcds.ualberta.ca/wcds/wp-content/ uploads/sites/57/wcds_archive/Archive/2010/Manuscripts/p277 -292Rodenburg.pdf.
Rodenburg, J., and H. K. House. 2007. Field observations on barn layout and design for robotic milking. Sixth International Dairy Housing Conf. Proc. 701P0507e. https://doi.org/10.13031/2013 .22804 .

Salfer, J. A., J. M. Siewert, and M. I. Endres. 2018. Housing, management characteristics, and factors associated with lameness, hock lesions, and hygiene of lactating dairy cattle on Upper Midwest United States dairy farms using automatic milking systems. J. Dairy Sci. 101:8586-8594. https://doi.org/10.3168/jds.2017-13925.

Slettbakk, T., A. Jorstad, T. B. Farver, and D. W. Hird. 1990. Impact of milking characteristics and teat morphology on somatic cell counts in first-lactation Norwegian cattle. Prev. Vet. Med. 8:253-267. https://doi.org/10.1016/0167-5877(90)90083-T.

Tremblay, M., J. P. Hess, B. M. Christenson, K. K. McIntyre, B. Simink, A. J. van der Kemp, L. G. de Jong, and D. Döprer. 2016. Factors associated with increased milk production for automatic milking systems. J. Dairy Sci. 99:3824-3837. https://doi.org/10 $.3168 /$ jds.2015-10152.

Wagner-Storch, A. M., and R. W. Palmer. 2003. Feeding behavior, milking behavior, and milk yields of cows milked in a parlor versus an automatic milking system. J. Dairy Sci. 86:1494-1502. https:// doi.org/10.3168/jds.S0022-0302(03)73735-7. 